\title{
Gender Roles Representation in Television Advertisements: Implications for the Nigerian Girl-Child and Role Modelling
}

\author{
By Grace Iember Anweh ${ }^{*}$
}

\begin{abstract}
Gender roles portrayal in the mass media has been a contending issue among researchers in the academia, government and non-governmental bodies. Findings have persistently reflected the negative impact especially on the female gender. Due to the fact that some recent studies have reported the improvement in the representation of these gender roles as a result of the changing roles of males and females in societies in some countries away from Nigeria, this study was undertaken to unveil the current portrayal of gender roles in television advertisements and the possible implications on role modelling and the Nigerian Girl-Child. Content analysis of 114 advertisements from Nigerian Television Authority (NTA) and Africa Independent Television (AIT) was conducted. In addition, data was collected through Focus Group Discussion (FGD) of 21 participants from three selected states within the north central zone of Nigeria comprising female primary school pupils between the ages of 7-10. Anchored on the social learning theory by Albert Bandura, the study found that males and females are still portrayed in stereotyped gender roles like the professional or career man and the effective house wife or mother respectively. The study conclude that, the persistence of gender roles in television advertisements can have adverse effects on the Nigerian girl - child, such as the lack of role models (except the perfect house wife and mother) this may hinder the process of role modelling and thus, her effective choices for self and societal development. The study, recommended that through research and other academic fora, advertisers should be sensitised to reflect the changing roles of males and females in the society in order to provide effective role models for younger girls. In addition, government is advised to enact laws and legislations that are favourable to women representation in the television.
\end{abstract}

Keywords: advertising, gender roles, role model, stereotype, television.

\section{Introduction}

As agent of socialisation, the mass media especially television are seen as an effective tool for radical and effective change. The media do not only play an important role in shaping the values of society, but also reflect those values, (Gallagher, 2005). The uniqueness of television, according to Obono and Madu (2010), is its ability to present audio, text and video at the same time as well as its characteristic of defined audience segmentation. This distinctiveness, the authors stressed, makes television stand out above radio, newspapers and magazines. The uniqueness of television as a demonstrative medium makes it an attractive and most desired medium for advertising purposes.

Advertising can reach geographically dispersed buyers efficiently (Kotler, 2003). From this angle, the concept of advertising becomes the lifeblood of many profit-oriented organisations including the mass media. In spite of these advantages, it has also attracted criticisms from scholars and activists due to its

* Lecturer, Department of Mass Communication, Benue State University, Nigeria. 
perceived adverse effects on society. One of the most emphasised issues is that of gender and gender roles representation and how it affects males and females but especially females (Brodolini, Giomi, Sansonetti \& Tota, 2013; DiSalvatore, 2010; Gunter, 1995). The controversial representation of gender roles in the mass media formed one of the major reasons for the adoption of the Beijing Platform for Action (BPFA) unanimously by 189 member states of the United Nations at the Fourth World Conference on Women in 1995 (Gallagher, 2005). The platform, the author maintained, cited media as one of the twelve "critical areas of concern." The BPFA's section $\mathrm{J}$ is dedicated to Women and the Media with two strategic objectives, one of which is to promote a balanced and non-stereotyped portrayal of women in the media (Gallagher, 2005). But whether this declaration has been followed judiciously by member countries is a question begging for answer.

It is documented that, through advertising, television sells values and attitudes to its target audiences thus influencing their life choices (Dilogini \& Shivany, 2015; Khandai \& Agrawal, 2012). Women are often represented in traditional roles as social beings such as housewives/homemakers/mothers or general caregivers, clerks or receptionists, sex objects and objects for decoration while men are portrayed as authoritative figures, the bread winner, ultimate possessor of power and endowed with the ability to think logically etc. (Ngari, 2013; Espinar-Ruiz \& González-Díaz, 2012; George \& Uhlenbrock, 2010; Gunter, 1995). Other recent studies such as those of Moorthi, Subhadip and Pansari (2014) conducted in India have however reported improvement in the portrayal of gender roles. They observed that there is a deviation from the norms of traditional roles for men and women, to current images reflecting modern men and women in societies. Other studies such as those of Holtzhausen, Jordaan and North (2011) in South Africa found that women are no longer portrayed as sex objects.

While on the surface these images in advertisements may appear harmless, a critical analysis may prove otherwise. By implication, role modelling is necessary to facilitate children's advancement or integration into society. A child with an effective role model may grow up to be more useful to society than one lacking this. Some researchers such as DiSalvatore (2010) lent credence to this when they observed that the reinforcement of such stereotypical roles hinders the different sexes from nurturing and exhibiting inherent potentials that could be beneficial to society. The importance of role modelling prompted Ruth Sealy and Val Singh's (2008) conclusion in their study that "Organisations and those involved in preparing future leaders need to recognise the importance of role modelling as an integral process in the identity construction and development of both women and men leaders and in the women and men who follow after them."

With the above background situating the images of males and females as portrayed in television advertising with its ability to influence norms and values, and the importance of role modelling and identity formation especially for younger ones, we ask ourselves, what then is the situation in Nigeria? Most studies done are outside Nigeria, with those in Nigeria concentrating more on the images of women in the print media. Thus, this study investigates how gender roles are represented in television advertisements and the possible implications for the Nigerian girl-child and the place of role modelling. 
The following are the specific objectives guiding the study.

1. To know the ways gender roles are represented in television advertisements.

2. To ascertain whether differences exist between the portrayal of males and females in television advertisements.

3. To establish the implications of television gender roles portrayal for role modelling and the Nigerian girl-child.

\section{Research Hypothesis}

Ho. There are no significant differences in the representation of males and females in television advertisements.

\section{Concepts Clarification and Review of Literature}

\section{Gender Role/Stereotypes and Portrayal in Television Advertising}

Bem (1981) in Chalabaev, Sarrazin, Fontayne, Boich'e, and Cl'ementGuillotin (2013) considered gender as the endorsement of traits and behaviours that characterise males (e.g., leadership, independence and aggressiveness) and females (e.g., sensitivity, sweetness, childcare). Roles becomes the specific activity(ies) assigned to a particular sex which they are expected to adhere to in order to be clearly differentiated from the opposite sex for example, the role of a woman is to be a wife and care for anything that has to do with the home. If a woman must work, then her duty is to be a receptionist or secretary in order to enhance the organisation's aesthetic image. This become stereotypes which Brodolini et al. (2013) defined as preconceived ideas, whereby males and females are arbitrarily assigned characteristics and roles determined and limited by their sex thereby forcing individuals to adhere to predetermined gender roles just because of their sex and regardless of their natural predispositions.

While advertising is recognised for its prominent roles in boosting and oiling the wheels of the economies of nations, there has been a general outcry from some quarters regarding the harmful nature of advertising to the same environments it is making efforts to improve. Most prominent is the role it plays in reinforcing gender roles and stereotypes that result in harmful effects on some groups in the society especially the female gender. Representation of gender roles varies depending on the society and cultural norms, but there are particular themes that have similar description characterising the female and male gender. Holtzhausen, Jordaan and North (2011) outlined some of the commonest themes in advertising especially with regards to the female gender roles. These include: Decorative and Homemaker, Sex object and Social being, Wife/mother and Product user. Some recent studies indicate a representation of women more as housewives, and mothers whose role is specifically to raise children (Ngari, 2013) while a study by Ali and Shahwar (2011) on "Men, Women and TV Ads: The Representation of 
Men and Women in the Advertisements of Pakistani Electronic Media" also showed an imbalance in the representation of males and females with the females on the negative side. A problematic aspect of advertising identified by Brodolini et al. (2013) remains the sexual objectification of the female body where more women than males are dressed in revealing clothing, with bodily postures or facial expressions that imply sexual readiness (Espinar-Ruiz \& González-Díaz, 2012; Holtzhausen et al., 2011). These gender roles were reinforced by the media in line with cultural patterns of the society.

Over the years, however, women status's improved greatly in terms of education and work outside the home. More women are now in different kinds of professions including those once considered the strict domains for men. Consequently, it is expected that the trend in women's representation in advertising also reflects their new status in society. Yet, some authors have argued that women are still portrayed with emphasis on the traditional roles (Ali, Ali, Kumar, Hafeez \& Ghufran, 2012). Even where women were featured in professional roles in advertising, it was rather in a negative than positive angle of uplifting women (Brodolini et al., 2013). Hence, with this recognition of the communication media as a critical area of concern in women's empowerment and societal development, it should be a thing of concern that the media in Nigeria may still be dominated by stereotyped portrayal of negative images of men and women which may hinder the development of insightful future leaders.

\section{Television and Advertising in Nigeria: A Marriage of Convenience}

The marriage between television and advertising is such that a break up or divorce will lead to the demise of both. While television needs advertising revenue to sustain broadcasting and daily operations of the stations, advertisers are also in business to sell. In other words, without the consumer, there would be no need for advertising. Yet, the consumers are scattered and heterogeneous with distinctive psychographic and demographics characteristics. Therefore, how will advertisers access these special consumers and beat competition? The answer lies in a medium which has the ability to influence convincingly. Research has established that television is the most viable medium transcending age, sex and literacy as well as other social/economic status. Accordingly, Miller (2003) observed that television is the first centralised cultural influence to permeate both the initial and final years of life as well as the years between. Advertising on the medium thus requires a huge budget.

Because advertisers are paying very high for television slots which usually range from 30 seconds to 60 seconds, they expect maximum result. For instance, NTA advertisement rate for a slot in prime time programme is $1,750.000$ (equivalent of $\$ 4,861.50$ ) for 30 seconds. ' (NTA Network, 2014). The cost of an advertisement on any of the channels basically depends on the air time. Therefore, advertisers parting with these huge amounts for just a matter of seconds call for maximum results. Similarly, television channels cannot afford to relinquish this

\footnotetext{
${ }^{1}$ NTA Network (2014). Retrieved from https://ces.to/N4xsya.
} 
huge amount. The result, therefore is that such channels must dance to the tune of the advertisers.

Stressing this point, Moriarty, Mitchell, and Wells, (2009) aver that media selection and message frequency are some of the factors that determine the design and effective execution of an advertising campaign. They maintain that, to reach the target customer effectively, the advertiser needs to have a good understanding of the media habits of its customers. Once the right combination of media is found, the question has to move on to how often the company should expose the message to the target audience in order to achieve a certain level of awareness and attract consumers to the advertised product or message. This implies that the 30-60 second adverts on television are not enough to reach the target audience if the exposure is not repeated as many times as possible. Nielsen (2014) shows that when viewers are paying more attention to a programme, they will also pay more attention to the ads that air within that programme. Based on this, advertisers who can afford it make it a point of duty to target those hours when potential consumers are believed to tune in to television channels - most likely the prime time period. This is where and when the representation of gender roles through product advertisements is emphasised with its ominous consequences.

\section{The Effect of Gender Roles Representation in Advertising}

That advertising has effects on its consumers is incontestable. The bone of contention is the nature of effects in relation to the portrayal of women - positive or negative and to what extent. Over the years, many empirical researches based on the hypodermic needle theory established the powerful influence of television over audience. Evidence from counter studies indicated limited effects. Yet these research findings do not categorically eliminate the fact that the media constitute a certain amount of influence whether reinforced or cultivated over a period of time. It is from the foregoing that George and Uhlenbrock (2010, p. 7) averred that: "Media content may be based on what happens in the physical world, but it singles out and highlights certain elements over others."

In general, media advertising relies on and reinforces societal cultural stereotypes of women. Consumers are exposed to a wide variety of advertising in different media every day, and from these exposures, certain thinking patterns evolve. Male supremacy and female subordination are often propagated through gender differentiation in advertising messages. Supporting this assertion, Eisend (2010) viewed that even though it is possible that advertisements mirror societal ideals, gender role portrayals can still have consequential notions of reinforcement of social and gender stereotypes on society. Trailing the same opinions, McClure (1999) suggested that viewers see the world through a cultural lens, believing that behaviours, characteristics and attitudes are constructed by society. Stereotypical gender roles can guide and shape behaviour by affecting the audience's perception of social reality (Lafky \& Duffy, 1996). Kolbert (1995) in Espinosa (2010) also observed the broad consensus among social scientists that there is indeed a connection between popular culture and behaviour, noting that among parents surveyed, they noticed direct evidence of the connection via imitated behaviour 
and language from their children. This therefore underscores the fact that consistent exposure to gender role stereotypes can lead to imitation. The consequence can be dire on society when the copied behaviour is not beneficial to societal growth. For instance, Geis et al. (1984) cited in Shrikhande (2003) opined that women may perceive the happy housewife stereotype as a cultural directive which in turn may lead them to put aside their own desires regarding career and personal life and replace them with the ideal presented through popular culture including advertisements. Furthermore, when the masses are repeatedly shown images of women as victims, sexualised or in domestic roles, they might likely accept those images as normal and will build their beliefs and values on them.

In addition, society is generally affected when stereotypical gender roles hinder a great percentage of the population from contributing to economic development. For instance, when women are rarely portrayed in advertising doing masculine jobs, this can restrict their effort to participate in careers that will help boost the economy of the society. Media advertising reflecting these stereotypes could further hinder women's ability to climb the corporate ladder.

Health wise, research evidence suggests that exposure to thin-idealised media advertisements has a "small but consistent" effect on women's well-being (Groesz, Levine, \& Murnen, 2002), by producing general declines in mood and body satisfaction and an increase in weight anxiety (Harper \& Tiggemann, 2007). As predicted by Fredrickson and Roberts (1997), the process of viewing such advertisement will make women see their physical appearance as though looking at an observer thus making the body and its appearance become more salient points of reference for women in describing the self after this form of media exposure (Harper \& Tiggemann, 2007). Some researchers believe that most advertisements prescribe female happiness and success to be tied to the normative constructions of the female body, which promote ultra-thinness as the preferred state of health and beauty as well as the most important form of self-improvement. Not only females suffer negative effects of gender roles representation in advertising in particular. Wood (1994, p. 3) captured the negative effect of gender roles stereotypes on even males from a respondent in a study conducted as follows:

I wouldn't say this around anyone, but personally I'd be glad if the media let up a little on us guys. I watch those guys in films and on TV, and I just feel inadequate. I mean, I'm healthy and I look okay, and I'll probably make a decent salary when I graduate. But I am no stud; I can't beat up three guys at once; women don't fall dead at my feet; I doubt I'll make 1 million bucks; and I don't have muscles that ripple. Every time I go to a film, I leave feeling like a wimp. How any of us guys would measure up to what's on the screen?

Providing emphasis based on the above submission, Pollack (1998) submitted that boys are confused by society's mixed messages and expectations for being male while Kimmel (2008) maintained that males feel the need to suppress their ability to express compassion and empathy in order to achieve society-appropriate masculinity and to not appear vulnerable or weak. Kimmel (2008) further averred that males do not necessarily maintain ideals sustained by society to impress 
women, but rather "to be positively evaluated by other men." By suppressing feelings that already exist, boys are more prone to depression, suicidal behaviours, and fighting than girls are (Espinosa, 2010). Such views from such studies confirms the assumption that unfavourable role representation can impact society negatively.

It is the view of the researcher (subject to empirical testing) that one of the negative consequences of gender roles in advertising is the restriction of women in educational training in terms of courses of study as well as the eventual decision to avoid professions that are capable of upgrading their status in society. It is common to encounter higher educational institutions in Nigeria with overpopulated social sciences, humanities and art courses, while the science and technology faculties are practically empty of students. There is no gainsaying that a welldeveloped society is one in which qualified human resources man every section of the economy.

\section{Theoretical Framework}

This paper finds footing in Bandura's social learning theory which advocates that people learn as a result of their interaction within a social context. Nabavi (2012) notes that, by separately observing the behaviours of others, assimilation of behaviour observed is activated in the individual thus leading to learned behaviour especially if the observed behaviour is accompanied with reward. To Bandura, imitation is the actual reproduction of the observed behaviour. In other words, the principles of social learning are characterised by observation, imitation and modelling where the people being observed are models. Therefore, when observed behaviours from people considered models are imitated, learned behaviour has occurred (Newman \& Newman, 2007). By implication, children's exposure to television images such as those portrayed in advertisements can result in a modelling process where the observer may want to imitate similar behaviour. This calls for effective images of such television models in order to enhance the modelling process for the upcoming child for informed decision towards selfidentity.

\section{Methodology}

This research adopted quantitative Content analysis and Focus Group Discussion (FGD).

\section{Content Analysis}

Content analysis has often been used by researchers to examine message units (such as commercials) in studying advertising. Therefore, the researcher considered this design because a substantial part of data required to analyse the issue at hand involves critical insight into advertising contents for clear understanding of the messages. 
The population of study for the content analysis otherwise called universe comprised of 472 advertisements recorded from Nigerian Television Authority (NTA) and Africa Independent Television (AIT), representing public and private stations respectively. For the sample size, 114 advertisements representing one appearance were analysed. The advertisement samples analysed were those transmitted on prime time, which is the preferred segment for commercials by most advertisers. This period was considered because it is the time when most of the target audience retire from activities of the day to lounge before a television set in order to catch up with programmes. To arrive at this, the study looked at researches conducted regarding television advertising and viewership. Selecting the most popular channels and time to obtain samples is thus consistent with the research practices of other researchers (Bretl \& Cantor, 1988; Ibroscheva, 2007; Holtzhausen et al., 2011).

The procedure adopted is explained further below. First, the researcher purposively selected NTA and AIT stations which represent, public and private ownership. The reason for the choice of these channels was based on the desire for both private and public ownership to be represented. In addition, these channels were considered because they are widely viewed across the country as they have stations in majority of the states and their signals are equally accessible via satellite. The researcher then determined the period of coverage. Since most stations' programming is on quarterly basis, the first and third quarters which constitute a period of six months, spanning from January to March and July to September, 2017, were considered. The reason for the choice of these periods was that advertising is repetitive in nature hence choosing first and second quarters may result to duplication of the advertisements. However, with the selection of first and third quarters, more advertisements that were not placed in the first quarter were likely to be captured. Tuesdays and Thursdays were judgementally selected for recording of advertisements on NTA channel while Mondays and Fridays were considered for AIT. This was to allow the researcher the opportunity to personally record such advertisements. Furthermore, each TV channel was watched within the time bracket of 7-10 p.m. considered prime time. This was considered the most ideal time since it is a period when most people retire from their various activities of the day to relax before the screens to catch up on programmes. The period is also one which advertisers manipulate to advantage. In total, 472 commercials were recorded, 168 from AIT and 304 from NTA with NTA airing more advertisements than AIT during the period of coverage. After excluding duplicates, public service announcements and those in which the main character was not identifiable, the final sample consisted of 114 commercials for coding purpose.

Coding framework for this study was adopted from a composite of previous studies in the area under focus (Ibroscheva, 2007; Mwangi, 1996; Nasif \& Gunter, 2008; Bretl \& Cantor, 1988; Eisend, 2010). According to Kuhn (1970 as cited by Macnamara 2005), the scientific requirement for deduction should be based on past research, theories and bodies of evidence. By basing the adoption of coding framework on past research, this study adapts to scientific practices. The unit of measurement for this study was based on the appearances of male or female 
characters in advertisements as the central character. Categories studied include collecting data on the central character playing a major role in a commercial by virtue of either speaking the longest in a commercial or having the most prominent visual exposure. The following variables were coded and are defined as follows:

- Central figure: This is the main character or protagonist in the advertisement. The review here is based on whether the character is male or female. It is classified as: 1 - Male and 2 - Female.

- Voicing: This variable has to do with the manner in which the central character was presented or appeared in the commercial - whether talking or not. The central character was categorized based on the nature of their appearance in the commercial: 1 - Voice over; 2 - Visually speaking; 3 Visually not speaking.

- Mode: This variable was to help determine whether the central figure in the advertisement represented the product and the manner in which the representation occurred. This was coded as: 1 - Product user; 2 Presenter; 3 - Product authority; 4 - Decorative; 5 - Other.

- Product Type: This had to do with the kind of product or service advertised. This variable was classified according to the following categories: 1 - Body/personal care (lotions, beauty products, perfumes, bathing soap, toothpaste, shavers, clothes etc.); 2 - Food; 3 - Households (cleaning products, medicine); 4 - Household appliances (fridge, microwave, furniture etc.); 5 - Telecommunication (communication networks, radio, television, etc.); 6 - Automobiles; 7 - Sports; 8 - Services (communication, bank, insurance, hotel, electricity); 9 - Leisure (alcohol, beverages and soft drinks); 10 - Other.

- Setting: This was to help determine the environment in which the central figure was portrayed in the advertisement. The central character was categorised according to whether he/she was depicted in: 1 - Home (living room, kitchen, bedroom, bathroom, home compound); 2 - Store (supermarket/market/shop); 3 - Workplace; 4 - Leisure (bar, restaurant); 5 - Outdoor (street; beach, field, forest, playground, sport); 6 - Other.

- Role: What specific role was the male or female playing in the advertisements? This was considered under the following codes: 1 Parent; 2 - Household chores; 3 - Worker (informal jobs); 4 Professional; 5 - Celebrity (popular musician, actor, sports star, comedian etc.); 6 - Spouse; 7 - Partner; 8 - Sports Person; 9 - Other.

- Sexuality: This had to do with whether the man or woman as the central character was portrayed in a suggestive manner that could be termed as objectification. Categories studied under this theme included: 1 - Common dressing (everyday dress excluding underwear and short skirts); 2 Suggestive clothing (clothing which partially exposes the body such as tight skirts and trousers, unbuttoned blouses, and mini-skirts); 3 - Partially clad (underwear, bathing suits, workout outfits); 4 - Nude (actual nudity, suggestive nudity - holding a cloth to conceal genitals or breast); 5 - 
Stance (suggestive posing); 6 - Intimate contact (kissing, embracing, general body language with implication); 7 - Other.

- Age: This variable means the age category within which the male or female central character falls. This was considered under the following: 1 - Young; 2 - Middle age; 3 - Old and 4 - Not sure.

The coding instruction guide was carefully prepared to give detailed information and guide to the coders to enhance their understanding of the recorded advertisements and what to look out for. Coding sheets were used to record themes observed from the recorded advertisements. This was done with the assistance of two trained coders with an adequate coding instruction guide to enhance ease of understanding. For Inter-coder Reliability, pilot coding was conducted using 10 local television commercials recorded from NTA Makurdi station. This was to help fine tune the variables studied. With adequate guidance by the researcher, two trained coders coded 10 advertisements in order to ensure the reliability of the instrument before the actual coding. It was important to conduct a pilot test to determine whether the coding sheet was perfect and able to capture the desired data required to address the key issues investigated (Pillay, 2008). The pilot test offered the needed opportunity to train the two external coders that were used in order to attain inter-coder reliability.

Furthermore, since there were categories with sub categories in them to be studied, the inter-coder reliability between the coders was determined using Scott's reliability (Scott's pi index) test as recommended in Krippendorff (2004) which, according to Holst, corrects not only for the number of categories in the category set, but also for the probable frequency with which each is used. Each coder coded a one-hour tape for advertisements that was equivalent to $10 \%$ of the total sample for inter-coder reliability. The coefficient calculation is as follows:

Percentage of agreement=(Total correct-Total incorrect)/Total number measured

The over-all number of advertisements coded by both coders from a one-hour tape was 10. The total number of categories for each advertisement was seven. Therefore, the total number measured becomes 10 times seven, which equals 70 , $(10 \times 7=70)$. Conversely, both coders disagreed on three cases; hence the total number incorrect was three.

Percentage of agreement was calculated thus:

$$
(70-3) / 70=.96
$$

Note: 0 (perfect disagreement) < pi $>1$ (perfect agreement). Overall inter-coder reliability coefficient was between .96 which shows a near perfect agreement between the coders on the categories studied. 


\section{Focus Group Discussion}

Focus group discussion (FGD) was also adopted as a method for this study to complement the quantitative content analysis. According to Collis and Hussey (2013), a FGD is a form of qualitative research in which a group of people are asked about their perceptions, opinions, beliefs and attitudes towards a product, service, concept, advertisement, idea, or packaging. With the nature of research objective three, which sought to establish the implications of gender roles portrayal in advertisements for role modelling and the Nigerian girl-child, the need for focus group discussion was imperative.

The population of the focus group method comprised primary school female pupils in the north central zone of Nigeria. A focus group comprising 7 participants each from three selected states of the north central zones of Nigeria totalling 21 represented the sample size. These states include Benue State, Plateau and Abuja. Reasons for this selection were based on the lean resources of the researcher. Hence, a selection based on proximity and convenience to the researcher was considered appropriate for ease and manageability. The selection of pupils at the primary level of education hinged on the fact that identity formation starts early in life but becomes more prominent when the child begins schooling. At this stage too, the need for a role model to help define self-identity becomes higher. Therefore, the researcher considered this factor apt for this study to obtain the views of the primary school pupils regarding the issue under discourse. Similarly, the choice of age falls within the primary school age category. However, the years 7 to 10 was in order to settle for respondents who were old enough to comprehend the issue under study when properly guided.

These children were selected purposively within the same area but distant enough from each other to avoid too much familiarity with each other which could have negative impact on the discussion. In addition, the selection of the participants was done with carefulness to ensure that there were no two children from the same families or schools.

Consent was sought and obtained from parents of the selected children who were first given a recorded tape of some selected advertisements that were used for the content analysis to play for the children to watch as many times as possible. These advertisements include Mortem and Dettol. These products were considered because they had themes representing the traditional roles of males and females such as the mother or housewife/caregiver and the professional or career person. The main characters in these products represent the role models. In addition, each of the selected advertisements involved children who were basically participants in the advertisements as well as intended consumers for the advertised products. On the stipulated day for the sessions, the same advertisements were played for the children to determine their level of awareness and exposure before the discussion commenced. Two well trained research assistants and facilitators were employed and given well-structured scripts to facilitate the group discussions in Plateau State and Abuja while the researcher personally handled the group in Benue state. 


\section{Findings}

A total number of 472 commercials were recorded from AIT and NTA channels. After the elimination of advertisements with inanimate figures, public service commercials as well as those without well-defined central figures, a total of 114 advertisements were coded for male and female if presented as the central figure. A total of $63(55 \%)$ males were coded while $51(45 \%)$ were females making up the total of 114 samples coded.

Out of the seven categories coded, some sub categories as originally captured on the coding sheet were collapsed into others to enhance ease of analysis and testing of hypothesis and also for the fact that most of them did not yield results during the coding. The following categories were collapsed: product type has the following collapsed sub categories - household products, automobiles, sports products and leisure. Role category has the following collapsed items: spouse, partner, sports person, entertainer. In sexuality, nude is collapsed into suggestive clothing.

Figure 1. Central Figure Representation in Advertisement by Gender

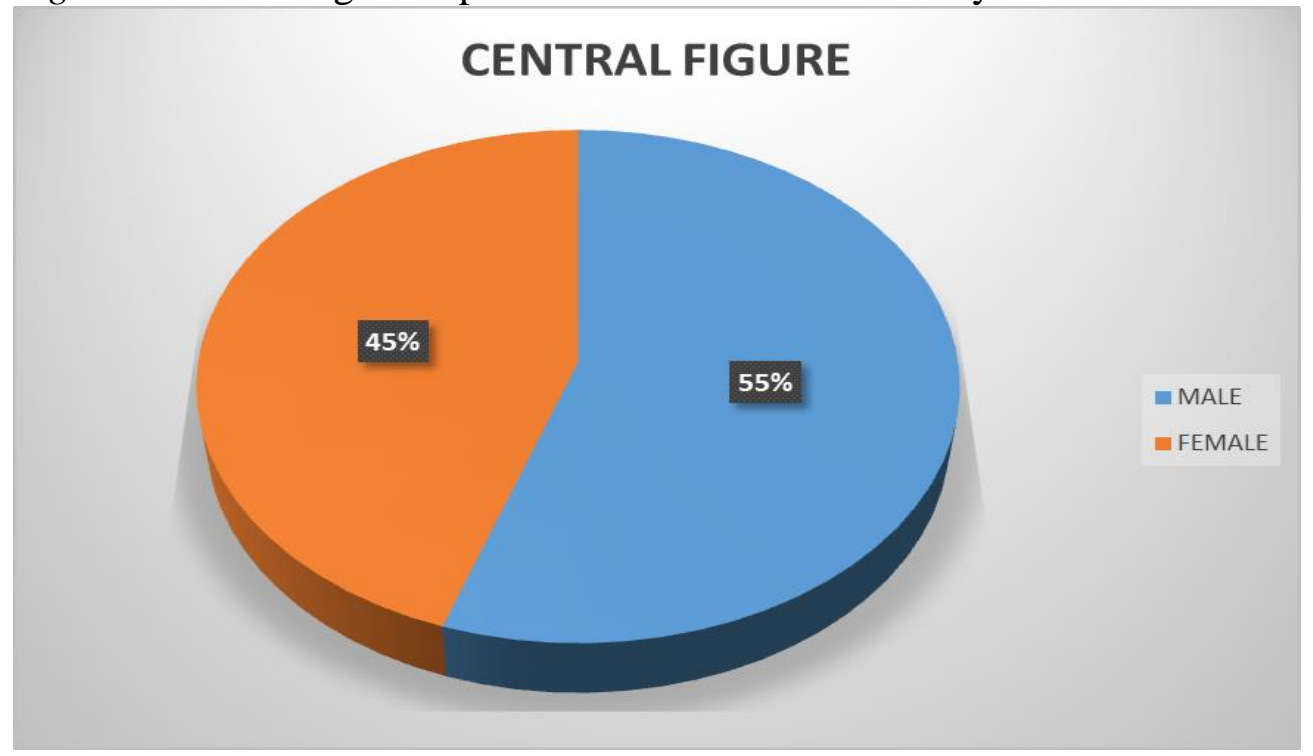

Source: Field work 2017.

Figure 1 indicates that, out of the total central figures coded for this study, males constitute $63(55 \%)$ representing the highest, while female central figures follow closely with $51(45 \%)$. The data is an indication that although more males than females are used as central figures in advertising products and services, the two genders are substantially used in television advertising unlike in the past when females were used only in decorating products and not as central figures. 
Table 1. Distribution of Central Figure Representing Various Categories

\begin{tabular}{|c|c|c|c|c|c|}
\hline Variable & Category & Male F (\%) & Female F (\%) & Total F (\%) & Chi square \\
\hline \multirow{7}{*}{ Product } & Body/personal care & $10(38.5 \%)$ & $16(61.5 \%)$ & $26(22.8 \%)$ & \\
\hline & Food & $12(35.3 \%)$ & $22(64.7 \%)$ & $34(29.8 \%)$ & \\
\hline & Household appliances & $8(89 \%)$ & $1(11 \%)$ & $9(7.9 \%)$ & \\
\hline & Services & $9(69.2 \%)$ & $4(30.8 \%)$ & $13(11.4 \%)$ & \\
\hline & Telecommunication & $19(76 \%)$ & $6(24 \%)$ & $25(22 \%)$ & \\
\hline & Other & $5(71.4 \%)$ & $2(28.6 \%)$ & $7(6.1 \%)$ & \\
\hline & Total & 63 & 51 & $114(100 \%)$ & $\begin{array}{l}21.344 \\
(d f=5)\end{array}$ \\
\hline \multirow[t]{5}{*}{ Age } & Young & $13(31.7 \%)$ & $28(68.3 \%)$ & $41(35.9 \%)$ & \\
\hline & Middle age & $37(80.4 \%)$ & $9(19.6 \%)$ & $46(40.4 \%)$ & \\
\hline & Old & $8(53.3 \%)$ & $7(46.7 \%)$ & $15(13.2 \%)$ & \\
\hline & Not sure & $5(41.7 \%)$ & $7(58.3 \%)$ & $12(10.5 \%)$ & \\
\hline & Total & 63 & 51 & $114(100 \%)$ & $\begin{array}{c}3.148 \\
(d f=3)\end{array}$ \\
\hline \multirow[t]{7}{*}{ Setting } & Home & $7(17.5 \%)$ & $33(82.5 \%)$ & $40(35.1 \%$ & \\
\hline & Store/shopping centre & $0(0 \%)$ & $7(100 \%)$ & $7(6.1 \%)$ & \\
\hline & Workplace & $27(100 \%)$ & $0(0 \%)$ & $27(23.7 \%)$ & \\
\hline & Outdoor & $9(69.2 \%)$ & $4(30.8 \%)$ & $13(11.4 \%)$ & \\
\hline & Leisure & $15(71.4 \%)$ & $6(28.6 \%)$ & $21(18.4 \%)$ & \\
\hline & Other & $5(83.3 \%)$ & $1(16.7 \%)$ & $6(5.3 \%)$ & \\
\hline & Total & 63 & 51 & $\begin{array}{l}114 \\
100\end{array}$ & $\begin{array}{l}58.735 \\
(d f=5)\end{array}$ \\
\hline \multirow[t]{6}{*}{ Role } & Parent/house chores & $12(22.2 \%)$ & $42(77.8 \%)$ & $54(47.4 \%)$ & \\
\hline & Worker & $9(75 \%)$ & $3(25 \%)$ & $12(10.5 \%)$ & \\
\hline & Professional & $28(100 \%)$ & $0(0 \%)$ & $28(24.6 \%)$ & \\
\hline & Celebrity & $8(66.7 \%)$ & $4(33.3 \%)$ & $12(10.5 \%)$ & \\
\hline & Other & $6(75 \%)$ & $2(25 \%)$ & $8(7.0 \%)$ & \\
\hline & Total & 63 & 51 & $\begin{array}{l}114 \\
100\end{array}$ & $\begin{array}{r}50.034 \\
(d f=4)\end{array}$ \\
\hline \multirow[t]{3}{*}{ Voicing } & Virtually speaking & $13(72.2 \%)$ & $5(27.8 \%)$ & $18(15.8 \%)$ & \\
\hline & Virtually not speaking & $8(53.3 \%)$ & $7(46.7 \%)$ & $15(13.2 \%)$ & \\
\hline & Voice over & $62(76.5 \%)$ & $19(23.5 \%)$ & $81(71.0 \%)$ & $\begin{array}{c}.509 \\
(d f=2)\end{array}$ \\
\hline \multirow[t]{6}{*}{ Mode } & Product user & $14(37.8 \%)$ & $23(62.2 \%)$ & $37(32.5 \%)$ & \\
\hline & Product presenter & $17(65.4 \%)$ & $9(34.6 \%)$ & $26(22.8 \%)$ & \\
\hline & Authority & $24(82.85)$ & $5(17.2 \%)$ & $29(25.4 \%)$ & \\
\hline & Decorative & $4(25 \%)$ & $12(75 \%)$ & $16(14 \%)$ & \\
\hline & Other & $4(66.7 \%)$ & $2(33 \%)$ & $6(5.3 \%)$ & \\
\hline & Total & 63 & 51 & $\begin{array}{l}114 \\
100\end{array}$ & $\begin{array}{l}23.591 \\
(d f=4)\end{array}$ \\
\hline \multirow[t]{6}{*}{ Sexuality } & Common & $53(62.4 \%)$ & $32(37.6 \%)$ & $85(74.6 \%)$ & \\
\hline & Suggestive & $0(0 \%)$ & $5(100 \%)$ & $5(100 \%)$ & \\
\hline & Partially clad & $2(20 \%)$ & $8(80 \%)$ & $10(8.8 \%)$ & \\
\hline & Intimate contact & $4(50 \%)$ & $4(50 \%)$ & $8(7 \%)$ & \\
\hline & Other & $4(66.7 \%)$ & $2(33.3 \%)$ & $6(5.3 \%)$ & \\
\hline & Total & 63 & 51 & $\begin{array}{l}114 \\
100\end{array}$ & $\begin{array}{l}14.143 \\
(d f=5)\end{array}$ \\
\hline
\end{tabular}

Source: Field Work 2017.

From the data presented in Table 1 evidence from the product category indicates that, food represents the highest category of product advertisements on 
television within the period studied at $29.8 \%$ (34) with the female gender constituting the major central figure in the category with $64.7 \%$ (22) while the male gender was used as the central figure $33.3 \%$ (12). This category is closely followed by Body/Personal care product at $22.8 \%$ (26). In this category, the female gender still constituted the highest percentage as the central figure at $61.5 \%$ (16) and male $38.5 \%$ (10). The rest of the products include, telecommunication with $22 \%$ (25) with 6 females representing $24 \%$ and 19 males (76\%). Services has $13(11.4 \%)$ with $4(30.8 \%)$ females as central figures and $9(69.2 \%)$ males as central figure. Household appliances is represented with $9(7.9 \%)$ with males 8 $(89 \%)$ as central figure while female central figure in this category is $1(11 \%)$. The remaining $7(6.1 \%)$ with $2(28.6 \%)$ female and $5(71.4 \%)$ males fell into the category whose product nature did not fall into any of the other categories presented above.

Table 1 shows more women in products like food and body/personal care products while the male gender was represented more for telecommunication, services and household appliances.

In the age variable as shown in Table 1, 46 (35.9\%), 41 (40.4\%), $15(13.2 \%)$ represented the central figures in the age bracket of middle age, young and old respectively while the remaining $12(10,5 \%)$ are those whose age bracket could not be ascertained. From these figures, the female gender was used the most as central figure at $28(68.3 \%)$ in the young category to advertise products while males are $13(31.7 \%)$. In the middle age category, the males constitute the highest percentage $37(80.4 \%)$ with females taking the rest of $9(19.6 \%)$. The rest making up $53.3 \%$ and $46.7 \%$ almost evenly distributed represented males and females in the "old" category. The rest of $7(41.7 \%)$ for males and $8(58.3 \%)$ for females were those whose ages could not be ascertained. Data here indicates that more females than males in the young age category are used, while for the middle age, more males than females are used. Only in the old category are males and females used almost at the same level.

Information conveyed under the 'Setting' variable shows advertisements presented in home setting or environment at the highest with $35.1 \%$ (40), workplace environment $23.7 \%$ (27), leisure $18.4 \%$ (21), outdoor $11.4 \%$ (13), store or shopping centre $6.1 \%$ (7) and other 5.3\% (6). Arising from this result are $82.5 \%$ females and $17.5 \%$ males as central figures for the home setting. Workplace has $100 \%$ (27) males represented under this environment, with $71.4 \%$ males and $28.6 \%$ females portrayed as central figures in the leisure setting. In the outdoor category, males still outnumbered females as central figures with $69.2 \%$ and $30.8 \%$ respectively while females were represented at the store or shopping centre setting at $100 \%$ with no single male represented as central figure. The rest comprising $5(83.3 \%)$ males and $1(16.7 \%)$ female belonged to a category that was not specified. Therefore, more women than men were portrayed in the home and shopping centre environment while their male counterparts had more portrayal in the workplace, outdoor and leisure environments.

Commercials observed with regards to role played showed the sub categories of Parent/household chores as $47.4 \%$ (54), Professional $24.6 \%$ (28), Worker $10.5 \%$ (12), Celebrity $10.5 \%$ (12) and other $7 \%$ (8). The data indicate that under 
the "parent" sub category, women were represented the most at $77.8 \%$ (42) while men constituted $22.2 \%$ (12). At the professional level, men were represented more at $100 \%$ (28) with no single female portrayed in this role. More males than females were represented as central figures in the worker category at 75\% (9) and $25 \%$ (3) respectively. In the aspect of celebrity, the central figures portrayed are $66.7 \%$ males and $33.3 \%$ females while those whose roles were not clearly defined stood at $75 \%$ (8) males and $25 \%$ (4) females; $75 \%$ (6) males $25 \%$ (2) constitutes those whose role could not be ascertained. The implication of this data is that more women are represented as parents or doing house chores and shopping in advertisements while males are portrayed more as professionals and workers in different fields representing products.

Data acquired as represented in Table 1 also revealed that of the $81(71 \%)$ of Voice Overs in the commercials observed, more men than women were used at 62 $(76.5 \%)$ and $19(23.5 \%)$ respectively while those who were observed as Virtually Speaking represent $15.8 \%$ (18) with $13(72.2 \%)$ males and $5(27.8 \%)$ females while the last category are those who did not speak in the advertisements at all. This stood at $13.2 \%(15), 53.3 \%$ (8) males and $46.7 \%$ (7) females. This result implies that more men are used in Voice Over in advertising and are seen to be virtually speaking while women are more often only used as those central figures that do not speak for the product or service.

The Mode category as shown in Table 1 comprises of Product User category $32.5 \%$ (37), Product Authority 25.4\% (29), Product Presenter 22.8\% (26), Decorative $14 \%$ (16) and "Other" 5.3\% (6). From this data, more women are portrayed as central figures who are users of the product advertised. This is evidenced from the 23 (62\%) representing females and $14(37.8 \%)$ males. More men on the other hand than females are shown as representing the product advertised as authoritative figures at $24(82.8 \%)$ males and $5(17.2 \%)$ females. Product presenter and decorative has $17(65.4 \%)$ and 4 (25\%) males while females are $9(34.6 \%)$ and $12(75 \%)$ for the same categories. This entails that mostly, women are portrayed in advertisements as central figures who engage in the usage of the products with men closely following as central figures that act as authorities for the advertised products.

Sexuality as presented in Table 1 has other sub categories that include "Common" with the highest percentage of 74.6 (85), Partially Clad 8.8\% (10), Intimate Contact 7\% (8), Suggestive $4.4 \%$ and others $5.3 \%$ (6). From this data, it can be observed that, the males appeared mostly in common dressing at 53 $(62.4 \%)$ and females at $32(37.6 \%)$. Those who were partially clad constitute more females at $8(80 \%)$ than males at $2(20 \%)$. For engaging in intimate contact that emphasises a show of sexuality, the distribution is even between males and females at $4(50 \%)$ respectively, while $66.7 \%$ males and $33.3 \%$ females sexuality play fell in the option of "other". Therefore, the result here indicates that sexuality is not displayed in advertising in a negative form as the common type of dressing is mostly used but with more men represented than the females while the smallest percentage of sexuality displayed still shows women in the lead. 


\section{Results}

Research objective one aimed to establish how gender roles are portrayed in advertisements. As represented in table one under the "variable" column, data shows the different ways through which gender roles are played out in advertising. These include through the type of product advertised, age of the main character representing the product, the setting, the actual role played in the advertisement, the voicing, mode of representation and sexuality.

Research objective two sought to find out if differences existed in the way males and females are portrayed in advertisements. Table 1 shows seven categories and sub categories that were coded with Chi Square used to test each category to determine if there was any significant difference existing in the portrayal of the two genders.

In the product category, Chi Square $\left(\mathrm{X}^{2}\right)$ calculated of 21.344 with degree of freedom (df) as 5 at 0.05 level of significance with a table value of 11.07 confirms significant differences between males and females in the type of products they represent. The results show that women act more as central figures in food products and body/personal care products while the male central figures feature more prominently in telecommunication, household appliances and services. Similar differences were noted in the setting category. Data shows that advertisements portray women in the home as homemakers and people who do the shopping to keep the home. On the other hand, advertising portrays men as the gender that represents workplace, outdoor and leisure environments. Chi Square run confirms the result at 58.735 calculated against table value of p11.07 with d.f 5 at 0.05 level of significance.

For the Role category, we conclude that there is gender role play in television advertising since $\mathrm{X}^{2}$ obtained $=50.034$. d. $f=4$ at 0.05 level of significance is greater than $\mathrm{p}=9.488$. Table 1 shows that advertisements portray more women as parents and engaging in household chores than males. On the other hand, more men than women are portrayed as professionals in various fields, as workers and even as celebrities. The data for mode category indicates that more women are portrayed as product users and as decorative images for products against men who are portrayed as authorities and product presenters.

Objective three aimed to ascertain the implications of television gender roles portrayal for role modelling and the Nigerian girl child. The responses from the participants showed that, the children were exposed to the advertisements and had a basic knowledge of the story line of the advertisements. In the case of Mortem, the discussants' responses showed a high preference for the woman (mother) who was the main character in the advertisement and also represented the role model. Asked the reason why most of the children preferred or liked the woman most, answers indicated the ability of the woman to kill the mosquito. One particular child went further to give a detailed description of why her favourite in the advertisement is the mother.

The father and the boy are pursuing the mosquito but they can't kill it. So the mother just carry that thing in that long bottle and sprayed shuuuuuu, and the mosquito died 
so they are clapping for her (referring to the man and two children clapping for the mum; giggles).

In the second advertisement on Dettol (two on same products but different scenarios and actors), majority of the children identified with the role played by the mother who was able to give the child a thorough bath with Dettol while also attending to his minor injuries with the same product. The reasons attributed to the preference emerged from mother's ability to clean the boy. A child said "That is how my mummy used to bath me and junior at home." Pertaining to role model, the children's reaction and support for the woman and her super role in the advertisement is an indication that already, an identity formation process is established. In this case, the child sees the role of mother as care giver as the superior part to adopt or follow. On the second advertisement on Dettol which had a man as the doctor and main character representing the product, conflicting answers were obtained from the discussants. The various answers and inability of the children to determine their most preferred actor showed a clear case of not being able to identify a role model in the advertisement, basically because the male as the main character and most prominent in the advertisement is not consistent with their sex and hence does not represent a role model. Because females have biological endowments that make them female, it is natural for them to identify with a similar sex. Hence a man representing a product as a professional (doctor) may not really mean much for the girl-child. This could be attributed to the crisis encountered by the participants in defining their favourite actor where a man was the main character in the advertisement.

\section{Discussion of Findings}

When advertisers set out to promote their products in order to attract consumers, several strategies are employed. Most prominent is the gender (male or female) that will represent the product more successfully. Unlike in years past when studies revealed underrepresentation of females as central figures, the situation is different now, including the Nigerian scenario. Both males and females are used extensively as central figures in product representation.

In line with most studies conducted in the past and present (Espinar-Ruiz, \& González-Díaz, 2012; Holtzhausen et al., 2011; Shrikhande, 2003) regarding the representation of gender roles in product categories, there is evidence to prove that advertisers still persist in portraying women in food, body and personal care products while males are preferred choices for products such as household appliances, telecommunications and services. Type of product to a large extent determines the kind of appeals advertisers employ in order to sell goods or services. It will not be out of place to argue here that, body/personal care as well as food are major areas through which males and females are often stereotyped. For instance, it is considered a taboo in some traditions within African societies particularly in Nigeria for a man to be seen cooking for the family or doing other household chores such as cleaning especially when he is a married man. A man seen to be doing such chores is often tagged "woman wrapper," in other cases he is 
said to be bewitched by the woman, or the wife is tagged as the "controlling" type who makes her husband do "woman chores." Advertisers capitalise on these stereotypes to reinforce these values, thus establishing that certain attributes must be consistent with males and others for females thereby setting the pace for gender role - play. It is no wonder that this study, like many others, has proven that women are still considered as lacking the thinking capacity to analyse and evaluate complicated products such as household appliances. As such, the role of logical thinking is assigned to men while women must concentrate on food, body and personal care that are considered less tasking and rely mostly on emotional traits like love, joy, happiness, beauty etc.

Gender stereotypes analysed in advertisements for the present study also hold that the place of the woman is the home and if outside the home, then she should be in the market or shopping centre making adequate preparation to cater for the home. In the same vein, the man is seen as the bread winner who must do the manly things such as socialising with friends outside the home at leisure joints or working. Similar findings were discovered by Ngari (2013) in his study. Needless to point out that a great difference in the portrayal of gender roles in this category still dominates television advertising even with the changing roles of women in society. One can conveniently say that advertising is not being fair to the two genders. Practical examples in today's societies show that most men take care of the home as much as most women are bread winners and sometimes work more than two jobs outside the home to keep the family going or complement the man of the house. Some women are single mothers or even unmarried who provide not just for themselves but for family and extended families and as such, have equal or even more responsibilities than the man who has been stereotypically assigned the role of the working bread winner.

In addition, most women are career working women combining their professions and family successfully to improve self, family and the society. It is therefore unrealistic to continuously emphasise the role of the woman as a mother or parent who does nothing but care for the home and family and looks good at all times to be devoured by a hardworking man. Only a few men are shown in this role even though the society in which we live is such that most men help their wives in these roles. Many studies have found support for this criticism (Ferrante, Haynes \& Kingsley, 1988). In the aspect of professional career, not a single female is considered good enough to play this role as it has completely been assigned to the male folk. In a similar study by Allan and Coltrane (1996, p. 14), the authors concluded that, "even when women were pictured in a work activity, they were 12 times more likely to be shown displaying stereotypically masculine traits." One is tempted to ask, what happens to the present day society where many women are in professional careers such as doctors, lawyers, engineers, technologists etc.? The advertisements analysed revealed that even in products where women are considered major consumers such as cleaning detergents, cooking oil, body care products etc., the use of men as a doctors or in other relevant professions to convey expert information about the product persists.

This study has also shown that more women than men are portrayed as product users and decorative protagonists. This finding was studied under the 
mode of presentation category with three sub categories - product user, product presenter, decorative and product authority. While male central figures were preferred to show authority for the product as well as present the product, women were considered relevant only as product users and decorative objects for products. This finding is also consistent with cultural beliefs that a woman is incapable of thinking logically the way a man does and therefore, she has to rely on the man. All a woman is good at is consuming the products, but when it comes to thinking and analysing the products to determine the beneficial attributes of the product, the male is the best option. The best a woman can achieve is using her beauty or sexuality to decorate the product or service advertised.

As appropriately captured by Bandura's social learning theory that people learn by imitating the actions of others in a social context, the portrayal of images of women and men in television which is a social medium that allows for learned behaviour, can lead to learned behaviour by younger females. It is thus no wonder that findings from the focus group discussion showed majority of the female children having a preference for the super women (role model) who were able to solve noticeable problems in the studied advertisements. This leaves the observer in no doubt that when presented with options of self-identity or other choices to be made, the girl child will not hesitate to consider the images of the "effective mother" observed in television. While being an effective mother is not a crime, it would be ideal if these role models in advertisements represent divergent roles such as career or professional women, performing duties considered to be in the male domain and so on. These should give the learning child various choices of role models and enable her make informed decision about who she may want to be when the need arises.

\section{Conclusion}

Arising from the findings, the study concludes that differences still exist in the representation of gender roles in television advertisements. Women are viewed as mothers and caregivers who should model for products like food and cleaning or other household chores while the males are professional career people, independent, working outside the home bread winners. The researcher believes that the persistence of these gender roles portrayal can have a negative impact on the Nigerian girl - child as a result of lack of role model figures to choose from except those conveying these traditional roles.

The study thus recommends that scholars, through incisive research articles and other relevant academic writings, should prevail on advertisers to reflect the changing roles of males and females in societies in the promotion of their products and services. This would provide options to young girls in need of role models for identity formation. It is also imperative for government to encourage favourable laws and legislations favouring women. Such laws will discourage television programmers as well as advertising regulatory bodies from allowing unfavourable images of women in advertisements on television. 
We believe that this study by its findings has contributed to the body of knowledge and literature by uncovering that in Nigeria, gender roles portrayal in television advertisements still emphasise traditional roles in line with findings from some countries and divergent from others which see advertisements in other countries as representing the current image of males and females in society. Notable also is the fact that little or no literature exists in Nigeria showing studies relating to analysis of contents of advertisements in television to establish the portrayal of gender roles. This study has therefore contributed to this area in addition to showing that emphasis on traditional stereotyped roles can lead to lack of role models thus hindering the girl - child from realising her potentials.

\section{References}

Alan, K., \& Coltrane, S. (1996). Gender displaying television commercials: A comparative study of television commercials in the 1950s and 1980s. Sex Roles, 35(3/4), 185-201.

Ali, B., Ali, R., Kumar, D., Hafeez, M. H., \& Ghufran, B. (2012). Gender role portrayal in television advertisement: Evidence from Pakistan. Information Management and Business Review, 4(6), 340-351.

Ali, S., \& Shahwar, D. (2011). Men, women and TV Ads: The representation of men and women in the advertisements of Pakistani electronic media. Journal of Media and Communication Studies, 3(4), 151-159.

Bretl, D. J., \& Cantor, J. (1988). The portrayal of men and women in US television commercials: A recent content analysis and trends over 15 years. Sex Roles, 18(9-10), 595-609.

Brodolini, F. G., Giomi, E. G., Sansonetti, S., \& Tota, A. L. (2013). Women and girls as subjects of media's attention and advertisement campaigns: The situation in Europe, best practices and legislations. European Union: Policy Department C: Citizens' Rights and Constitutional Affair. Retrieved from https://ces.to/aUAjwZ.

Chalabaev, A., Sarrazin, P., Fontayne, P., Boich'e, J., \& Cl'ement-Guillotin, C. (2013). The influence of sex stereotypes and gender roles on participation and performance in sport and exercise: Review and future directions. Psychology of Sport and Exercise, 14(2), 136-144.

Collis, J., \& Hussey, R. (2013). Business research: A practical guide for undergraduate and postgraduate students. London: Macmillan International Higher Education.

Dilogini, K., \& Shivany, S. (2015). Television Advertisements and Children's Behaviour: Parents' Experience base Study in the Post-War Context. Global Journal of Management and Business Research: E Marketing, 15(4), 1-12.

DiSalvatore, E. (2010). Portrayal of women in advertising. Retrieved from https://ces.to/ bNuNU8.

Eisend, M. (2010). A meta-analysis of gender roles in advertising. Journal of the Academy of Marketing Science, 38, 418-440.

Espinar-Ruiz, E., \& González-Díaz, C. (2012). Gender portrayals in food commercials: A content analysis of Spanish television advertisements. Observatorio (OBS) Journal, 6(4), 109-126. 
Espinosa, D. (2010). Gender roles in the media and debunking society's stereotypes: Glee as a Pop-culture reflection. Master dissertation, Winona State University. Retrieved from https://ces.to/ZN4Fpb.

Ferrante, C. L., Haynes, A. M., \& Kingsley, S. M. (1988). Image of women in television advertising. Journal of Broadcasting and Electronic Media, 3(2), 231-237.

Fredrickson, B. L., \& Roberts, T. (1997). Objectification theory: toward understanding women's lived experiences and mental health risks. Psychology of Women Quarterly, 21, 173-206.

Gallagher, M. (2005). More women in the media: The way forward. Report of the global Media Monitoring Project.

George, J., \& Uhlenbrock, M. (2010). Effects of advertisements on perceptions of women's leadership. Retrieved from https://ces.to/AtPXGQ.

Groesz, L. M., Levine, M. P., \& Murnen, S. K. (2002). The effect of experimental presentation of thin media images on body satisfaction: A meta-analytic review. International Journal of Eating Disorders, 31, 1-16.

Gunter, B. (1995). Television and gender representation. London: John Libbe.

Harper, B., \& Tiggemann, M. (2007). The effect of thin ideal media images on women's self-objectification, mood, and body image. DOI:10.1007/s11199-007-9379-x.

Holtzhausen, T., Jordaan, Y., \& North, E. J. (2011). The portrayal of women in South African television commercials. Southern African Business Review, 15(3), 162-173.

Ibroscheva, E. (2007). Caught between East and West? Portrayals of gender in Bulgarian television advertisements. Sex Roles, 57, 409-418.

Khandai, S., \& Agrawal, B. (2012). Impact of Television commercials upon: The Purchase behaviour of Urban Indian children. International Journal of Marketing and Technology, 2(4), 72-91.

Krippendorff, K. (2004). Reliability in Content Analysis: Some Common Misconceptions and Recommendations. Human Communication Research, 30(3), 411-433.

Nabavi, R. T. (2012). Bandura's social learning theory \& social cognitive learning theory. Retrieved from https://ces.to/xDxvXN.

Kimmel, M. (2008). Guyland. New York: Harper Collins Publishers.

Kotler, P. (2003). Kellogg on advertising and media. Hoboken: NJ John Wiley.

Lafky, S., \& Duffy, M. (1996). Looking through gendered lenses: Female stereotyping in advertisements and gender role expectations. Journalism \& Mass Communication Quarterly, 73, 379-388.

Macnamara, J. R. (2005). Media content analysis: Its uses, benefits and best practice methodology. Asia-Pacific Public Relations Journal, 6(1), 1-34.

McClure, L. (1999). Wimpy boys and macho girls: Gender equity at the crossroads. The English Journal, 88, 78-82.

Miller, T. (2003). Critical concepts in media and cultural studies. London: Routledge.

Moorthi, Y. L. R., Subhadip, R., \& Pansari, A. (2014). The changing roles portrayed by women in Indian advertisements: A longitudinal content analysis. Indian Institute of Management, Bangalore. Working Paper No.: 446.

Moriarty, S. Mitchell, N., and Wells, W. (2009) Advertising: principles and practice, Upper Saddle River. New Jersey: Pearson Education Inc.

Mwangi, M. W. (1996). Gender roles portrayed in Kenyan television commercials. Sex Roles, 34(3-4), 205-214.

Nassif, A., \& Gunter, B. (2008). Gender representation in television advertisements in Britain and Saudi Arabia. Sex Roles, 58, 752-760.

Newman, B. M., \& Newman, P. R. (2007). Theories of human development. Lawrence Erlbaum. 
Ngari, P. K. (2013). Portrayal of women in Kenyan television Advertisements. Master dissertation, University of Nairobi. Retrieved from https://ces.to/7Cl55k.

Nielsen. (2014). Advertising and Audiences: State of the Media. Retrieved from https://ces.to/qb2GR0.

Obono, K., \& Madu, M. (2010). Programming content of Nigerian broadcast media: towards an indigenizing paradigm. Retrieved from https://ces.to/YYK9jQ.

Pillay, N. (2008). The portrayal of women in television advertisements on sabc3: a reflection on stereotypical representation. Master dissertation, University of the Witwatersrand. Retrieved from https://ces.to/t8maKp.

Pollack, W. (1998). Real boys: Rescuing our sons from the myths of boyhood. New York: Henry Holt and Company.

Shrikhande, V. (2003). Stereotyping of women in television advertisements. Doctoral dissertation, University of Pune, India.

Sealy R., Singh V. (2008) The Importance of role models in the development of leaders' professional identities. In: James K. T., Collins J. (Eds.) Leadership Perspectives. London: Palgrave Macmillan.

Wood, J. T. (1994). Gendered media: The influence of media on views of gender. Retrieved from https://ces.to/w7Nbi1. 